ASTHMA

\title{
Adding salmeterol to an inhaled corticosteroid: long term effects on bronchial inflammation in asthma
}

J G Koopmans, R Lutter, H M Jansen, J S van der Zee

See end of article for authors' affiliations

\section{Correspondence to:} Dr J S van der Zee, Academic Medical Center, Department of

Pulmonology, F4-208,

$P$ O Box 22700 ,

1100 DE Amsterdam

The Netherlands;

j.s.vanderzee@amc.uva.nl

Received 14 August 2005

Accepted 4 January 2006

Published Online First

31 January 2006
Background: Addition of the long acting $\beta_{2}$ agonist salmeterol to inhaled corticosteroids leads to better symptomatic asthma control than increasing the dose of inhaled corticosteroids. However, little is known about the long term effects of adding salmeterol on the asthmatic inflammatory process, control of which is considered important for the long term outcome of asthma.

Methods: After a 4 week fluticasone run-in period, 54 patients with allergic asthma were randomised to receive twice daily treatment with fluticasone $250 \mu \mathrm{g}$ with or without salmeterol $50 \mu \mathrm{g}$ for 1 year in a double blind, parallel group design (total daily dose of fluticasone $500 \mu \mathrm{g}$ in both treatment groups). Primary outcomes were sputum eosinophil numbers and eosinophil cationic protein concentrations. Secondary outcomes were neutrophil associated sputum parameters and a respiratory membrane permeability marker. The effects on allergen induced changes were determined before and at the end of the treatment period.

Results: Adding salmeterol to fluticasone resulted in improved peak expiratory flow, symptom scores, rescue medication usage, and bronchial hyperresponsiveness ( $<<0.05$ for all). There was no sustained effect on sputum cell differential counts and cytokine concentrations during the treatment period or on changes induced by allergen challenge at the end of treatment ( $p>0.05)$. However, adding salmeterol significantly reduced sputum ratios of $\alpha_{2}$-macroglobulin and albumin during the treatment period ( $p=0.001)$.

Conclusions: The addition of salmeterol to fluticasone produces no sustained effect on allergen induced cellular bronchial inflammation but leads to a significant improvement in size selectivity of plasma protein permeation across the respiratory membrane. This may contribute to the improved clinical outcome seen in patients with allergic asthma when a long acting $\beta_{2}$ agonist is combined with inhaled corticosteroids.
A llergic asthma is currently considered primarily a chronic inflammatory disorder and repeated exposure to allergens may be important in the persistence of the disease. ${ }^{1}$ Other than avoiding exposure to risk factors, the use of inhaled corticosteroids is considered to be the mainstay for the treatment of allergic asthma. ${ }^{1}$ Regular use of inhaled corticosteroids in asthma is associated with prolonged improvement in exacerbation frequencies, symptom scores and lung function, as well as with a reduction in inflammatory cells in the airways. ${ }^{23}$ By contrast, $\beta_{2}$ agonists are principally regarded as bronchodilators and are advised to be used only in combination with anti-inflammatory treatment, except when used intermittently for the mildest form of asthma.

Several large clinical studies have now shown that adding a long acting $\beta_{2}$ agonist to inhaled corticosteroids leads to better symptomatic asthma control and lower exacerbation frequencies than increasing the dose of inhaled steroids. ${ }^{34}$ These findings suggest that adding a long acting $\beta_{2}$ agonist to inhaled corticosteroids exerts beneficial effects beyond smooth muscle relaxation. In vitro studies have also indicated a synergistic effect of combining long acting $\beta_{2}$ agonists and corticosteroids. ${ }^{5}$ Some short term clinical studies suggest an anti-inflammatory effect since lower numbers of EGl+ eosinophils and submucosal mast cells were found after adding salmeterol for 12 weeks. ${ }^{67}$ As a consequence, it has been proposed that the addition of a long acting $\beta_{2}$ agonist influences the underlying inflammatory process. In contrast, a recent study of bronchial biopsy specimens showed no additional anti-inflammatory effect of adding formeterol to low dose budesonide during 16 weeks of treatment. ${ }^{8}$ It should be emphasised that the long term clinical studies on adding salmeterol to inhaled corticosteroids were limited to clinical outcomes ${ }^{3}$ and did not evaluate bronchial hyperresponsiveness or surrogate inflammatory biomarkers such as airway eosinophils. These in turn are considered to be the ultimate driving force behind symptoms, the disability of asthma and, most importantly, the long term sequelae such as airway remodelling. ${ }^{9}{ }^{10}$ End points such as symptoms and lung function may favour the use of long acting $\beta_{2}$ agonists but provide little information about the pathophysiological features of the asthmatic inflammatory process. ${ }^{11}$ In addition, there are indications that the regular use of short acting $\beta_{2}$ agonists has pro-inflammatory effects; ${ }^{12}{ }^{13}$ this has led to concerns that adding a long acting $\beta_{2}$ agonist could lead to clinical masking of bronchial inflammation. ${ }^{14}$

A long term randomised clinical trial was performed to investigate whether the improved clinical outcomes resulting from adding salmeterol to fluticasone are accompanied by a prolonged effect on the underlying bronchial inflammatory process in asthma. After a run-in period with fluticasone $250 \mu \mathrm{g}$ twice daily, 54 patients with mild to moderate persistent allergic asthma were randomised to receive twice daily treatment with either fluticasone $(250 \mu \mathrm{g})$ or fluticasone/salmeterol $(250 / 50 \mu \mathrm{g})$ for 1 year. In addition, bronchial allergen challenges were performed 1 day before randomisation and at the end of the randomised treatment period to investigate the effect on allergen induced bronchial inflam-

Abbreviations: $E C P$, eosinophil cationic protein; $\mathrm{FEV}_{1}$, forced expiratory volume in 1 second; IL, interleukin; MPO, myeloperoxidase; $\mathrm{PC}_{2}$ histamine, concentration of histamine provoking a fall in $\mathrm{FEV}_{1}$ of at least $20 \%$; $\mathrm{RCE}_{\mathrm{s}}$, relative coefficient of excretion in induced sputum 
Table 2 Inflammatory parameters at start and end of the run-in period

\begin{tabular}{llll}
\hline & Start run-in & End run-in & p value \\
\hline Sputum eosinophils $\left(\times 10^{4} / \mathrm{g}\right)$ & $2.1(1.4)$ & $0.6(1.3)$ & $<0.001$ \\
Sputum eosinophils $(\%)$ & $3.2(1.3)$ & $0.8(1.3)$ & $<0.001$ \\
Sputum ECP $(\mathrm{ng} / \mathrm{ml})$ & $97(1.3)$ & $65(1.3)$ & 0.06 \\
Serum IL-5 $(\mathrm{pg} / \mathrm{ml})$ & $1.1(1.2$ & $0.6(1.2)$ & $<0.001$ \\
Sputum neutrophils $\left(\times 10^{4} / \mathrm{g}\right)$ & $28.1(1.3)$ & $29.1(1.3)$ & 0.98 \\
Sputum IL-8 $(\mathrm{ng} / \mathrm{ml})$ & $400(1.4)$ & $338(1.8)$ & 0.62 \\
Sputum $\mathrm{MPO}(\mu \mathrm{g} / \mathrm{ml})$ & $1308(1.3)$ & $1273(1.3)$ & 0.95 \\
RCE $\left(\times 10^{3}\right)$ & $76(1.2)$ & $52(1.2)$ & 0.006 \\
Sputum $\alpha_{2}$-macroglobulin $(\mathrm{ng} / \mathrm{ml})$ & $1388(1.3)$ & $21(1.3)$ & 0.04 \\
Sputum albumin $(\mu \mathrm{g} / \mathrm{ml})$ & $24(1.3)$ & 0.99 \\
\hline All values are expressed as geometric mean (SE). & \\
ECP, eosinophil cationic protein; IL, interleukin; MPO, myeloperoxidase; RCE, relative coefficient of excretion, \\
representing the ratio of $\alpha_{2}$-macroglobulin to albumin in induced sputum.
\end{tabular}

allergen was administered containing 100 biological units and was preceded by the inhalation of nebulised salbutamol. Levels of total and specific IgE were determined in the serum. ${ }^{16}$ Sputum induction and processing of whole sputum samples were performed as described elsewhere. ${ }^{17}$ Differential cell counts were expressed as number and percentage of cells excluding squamous epithelial cells. Sputum samples containing more than $80 \%$ squamous cells on differential cell counting were excluded from analysis. Levels of ECP, ${ }^{18}$ myeloperoxidase MPO, ${ }^{19}$ and $\mathrm{IL}-8^{20}$ were measured in sputum and levels of IL-5 in serum. ${ }^{21}$ Size selectivity of the respiratory membrane was analysed by measuring the relative coefficient of excretion in induced sputum $\left(\mathrm{RCE}_{\mathrm{s}}\right)$, which is the ratio of sputum concentrations of $\alpha_{2}$-macroglobulin to albumin. ${ }^{17} 22$

\section{Analysis of data}

Statistical analyses were performed using SAS Version 8.2 (SAS Institute Inc, Cary, NC, USA). The study was designed to have $80 \%$ power to be able to detect a $50 \%$ difference in geometric means of the primary outcomes between the groups with a sample size of 54 subjects. Changes over the run-in period were determined using the Wilcoxon signed ranks test or, in cases of normally distributed data, the $t$ test. Differences within and between the treatment groups were determined using mixed model ANOVA adjusted for differences at baseline. Differences in allergen induced changes were determined using ANCOVA and adjusted for baseline allergen induced changes. All $\mathrm{p}$ values are two tailed and levels $<0.05$ were considered significant.

Table 3 Mean differences in clinical and lung function parameters in the fluticasone/salmeterol (FP/S) group compared with the fluticasone (FP) group over the 1 year treatment period

\begin{tabular}{|c|c|c|}
\hline & $\begin{array}{l}\text { Mean difference } \\
\text { FP/S - FP }\end{array}$ & p value \\
\hline PEF morning $(1 / \mathrm{min})^{*}$ & $29(9)$ & $<0.001$ \\
\hline PEF evening $(1 / \mathrm{min})^{*}$ & $36(9)$ & $<0.001$ \\
\hline Symptom score morning (scale $0-4)^{*}$ & $-0.1(0.1)$ & 0.02 \\
\hline Symptom score evening (scale $0-5)^{\star}$ & $-0.2(0.1)$ & 0.01 \\
\hline $\begin{array}{l}\text { Short acting } \beta_{2} \text { agonist usage } \\
\text { (puffs } / \text { day) }\end{array}$ & -0.91031 & $<0.001$ \\
\hline $\mathrm{FEV}_{1}(\% \text { predicted })^{*}$ & $2.7(1.5)$ & 0.07 \\
\hline $\mathrm{PC}_{20}$ histamine (doubling doses) $\dagger$ & $0.7(0.3)$ & 0.02 \\
\hline
\end{tabular}

Values are expressed as *mean or tgeometric mean (SE). $\mathrm{PEF}$, peak expiratory flow; FEV 1 , forced expiratory volume in 1 second; $\mathrm{PC}_{20}$ histamine, concentration of histamine provoking a fall in $\mathrm{FEV}_{1}$ of at least $20 \%$.

\section{RESULTS}

Patients

Sixty patients agreed to participate in the study. Four did not fulfill the inclusion criteria after the run-in period and two withdrew during the run-in period for personal reasons, so 54 were randomised to receive one of the two treatment regimens. Patient characteristics, including age, dose of inhaled corticosteroids prior to the study and lung function parameters, were not significantly different between the treatment groups at baseline (end of run-in) (table 1).

Four patients in the fluticasone group failed to complete the study. Two of these patients withdrew 1 month after randomisation, one because of worsening of asthma symptoms and one was lost to follow up. The other two patients withdrew after 6 and 9 months of treatment, respectively, because of personal reasons. All patients in the fluticasone/ salmeterol group completed the study.
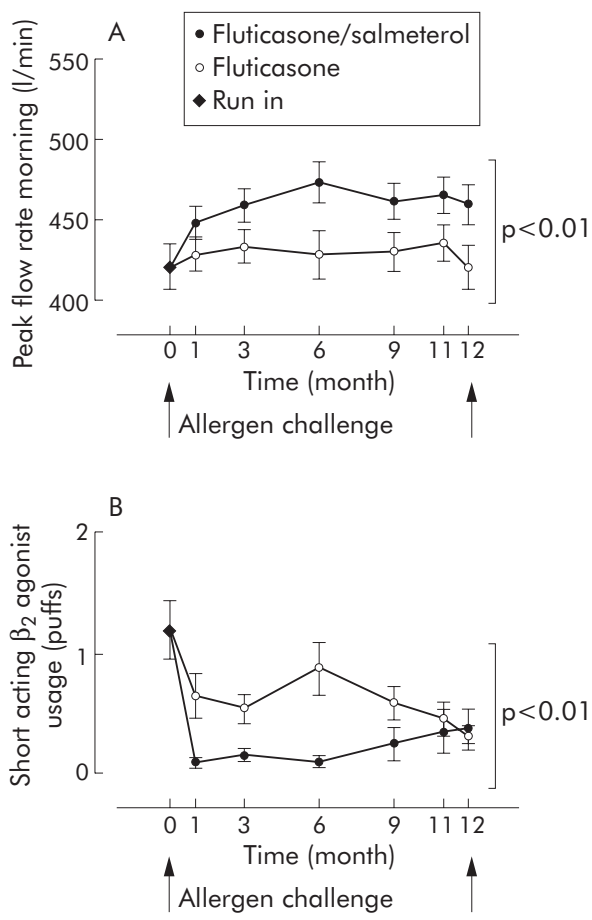

Figure 2 (A) Morning peak expiratory flow rate and (B) short acting $\beta_{2}$ agonist usage. Values are mean (SE). There were significant differences in morning peak flow recordings and short acting $\beta_{2}$ agonist usage between the two treatment groups $(p<0.01)$. 

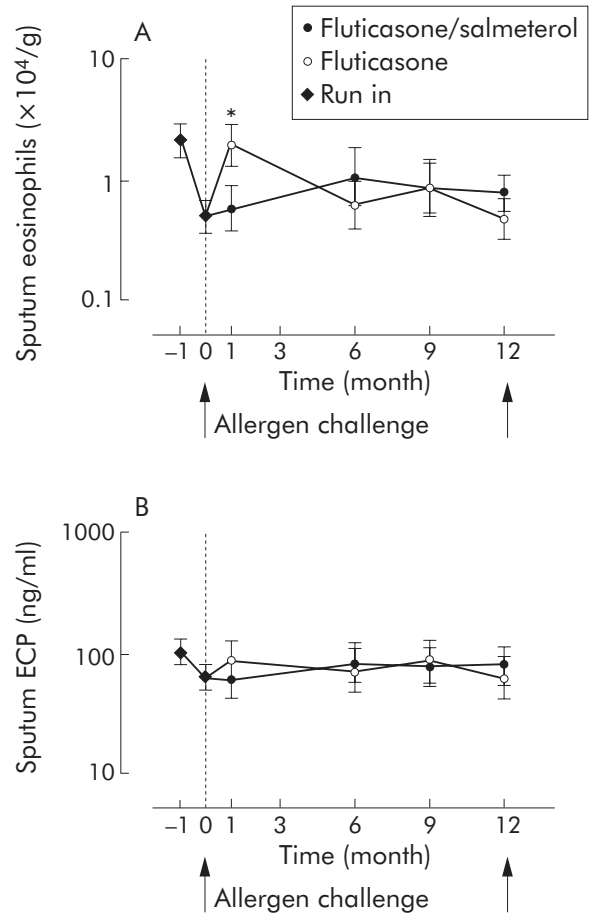

Figure 3 (A) Number of sputum eosinophils and (B) sputum eosinophil cationic protein (ECP) concentration. Baseline adjusted geometric mean (SE) values are shown. Overall, during the 1 year treatment period there were no significant differences between the two treatment groups in the number of sputum eosinophils or in the sputum ECP concentration $(p=0.72$ and $p=0.88$, respectively).

\section{Run-in period}

$\mathrm{FEV}_{1}$ and $\mathrm{PC}_{20}$ histamine improved significantly over the runin period which was preceded by a steroid washout period $(\mathrm{p}<0.001$, table 1$)$. Mean peak expiratory flow rates, asthma symptom scores, and short acting $\beta_{2}$ agonist usage recorded during the 2 weeks preceding the end of run-in visit (baseline) are shown in table 1 . Levels of the inflammatory parameters before and after the run-in period are shown in table 2 .

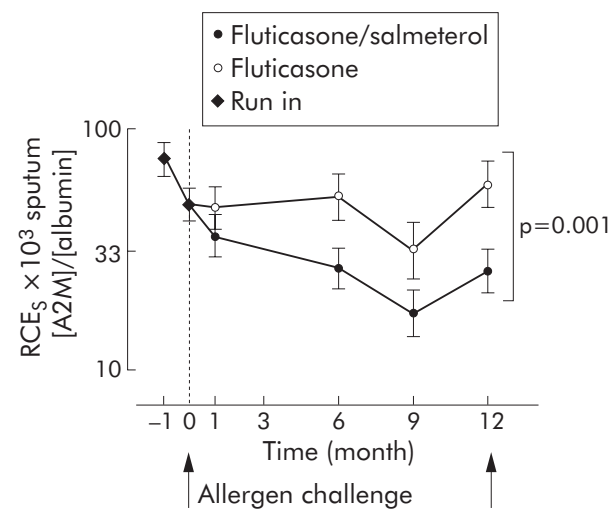

Figure 4 Relative coefficient of excretion $\left(\mathrm{RCE}_{\mathrm{s}}\right)$ during the run-in and the randomised treatment period. Baseline adjusted geometric mean (SE) values are shown. During the run-in period there was a significant decrease in the $\operatorname{RCE}_{s}(p=0.006)$. Overall, during the 1 year treatment period, the $\mathrm{RCE}_{\mathrm{s}}$ was significantly lower in the fluticasone/salmeterol group than in the fluticasone group $(p=0.001)$. The relative coefficient of excretion is the ratio of $\alpha_{2}$-macroglobulin to albumin in induced sputum.

\section{Randomised treatment period}

Lung function

Morning and evening peak expiratory flows, asthma symptom scores, and short acting $\beta_{2}$ agonist usage were significantly improved throughout the randomised treatment period in the fluticasone/salmeterol group compared with the fluticasone group (table 3, fig 2).

In the fluticasone/salmeterol group there was a trend for a higher $\mathrm{FEV}_{1}$ (table 3). $\mathrm{PC}_{20}$ histamine was significantly higher in the fluticasone/salmeterol group over the 1 year treatment period measured on visits after abstaining for 12 hours from the study medication (table 3 ), but there was no significant difference in $\mathrm{PC}_{20}$ histamine at the visit after 11 months of randomisation when patients abstained from the study medication for 36 hours (geometric mean (SE) baseline adjusted $\mathrm{PC}_{20}$ histamine $1.6(1.2) \mathrm{mg} / \mathrm{ml}$ in fluticasone group $v 1.9(1.3) \mathrm{mg} / \mathrm{ml}$ in fluticasone/salmeterol group, $\mathrm{p}=0.53)$. There were no differences in numbers or severity of exacerbations between the two treatment groups (results not shown).

\section{Sputum eosinophils and ECP}

The geometric mean number of eosinophils in the fluticasone/salmeterol group expressed as percentage difference from that in the fluticasone group varied significantly between visits $(p=0.019)$. After 1 month of randomised treatment the number of sputum eosinophils in the fluticasone/salmeterol group was $-71 \% \quad(95 \%$ CI -92 to -1.2 ) compared with the fluticasone group ( $p=0.048$, fig 3$)$. However, at other time points there was no significant difference between the groups (6 months: 56\% (95\% CI -71 to 741 ); 9 months $-0.14 \%$ (95\% CI -77 to 335 ), 12 months: $61 \%(95 \%$ CI -43 to 358$)$ ). Overall, during the 1 year treatment period there were no significant differences between the two treatment groups in either numbers or percentages of sputum eosinophils $(p=0.72$ and $p=0.85$, respectively, fig 3 ). The geometric mean ECP level in the fluticasone/salmeterol group was $5.7 \%$ lower than in the fluticasone group $(p=0.88)$. There were no indications that the difference varied between visits $(p=0.73)$. The $95 \%$ CI of the difference was $-57 \%$ to $+108 \%$, indicating that the true geometric mean ECP concentration in the fluticasone/ salmeterol group should have been more than 57\% lower than in the fluticasone group to be detected as significant, given the results of the study.

Sputum neutrophils, IL-8, MPO and serum IL-5 Sputum neutrophil numbers, sputum IL-8, sputum MPO, and serum IL-5 were not significantly different between the two treatment groups throughout the randomised treatment period $(\mathrm{p}=0.16,0.87,0.70$ and 0.23 respectively, data not shown).

Size selectivity of the respiratory membrane: relative coefficient of excretion $\left(R C E_{s}\right)$

Overall, during the 1 year treatment period the $\mathrm{RCE}_{\mathrm{s}}$ was significantly lower in the fluticasone/salmeterol group than in the fluticasone group ( $p=0.001$, fig 4$)$.

\section{Effect of adding salmeterol on allergen induced changes in bronchial inflammation}

There were no significant differences between the treatment groups in the change in $\mathrm{FEV}_{1}$ after the allergen challenges, which were preceded by the inhalation of salbutamol $(\mathrm{p}=0.81)$.

\section{Sputum eosinophils and ECP}

Sputum eosinophils (fig 5) and ECP concentrations increased significantly after the pre-randomisation allergen challenge 


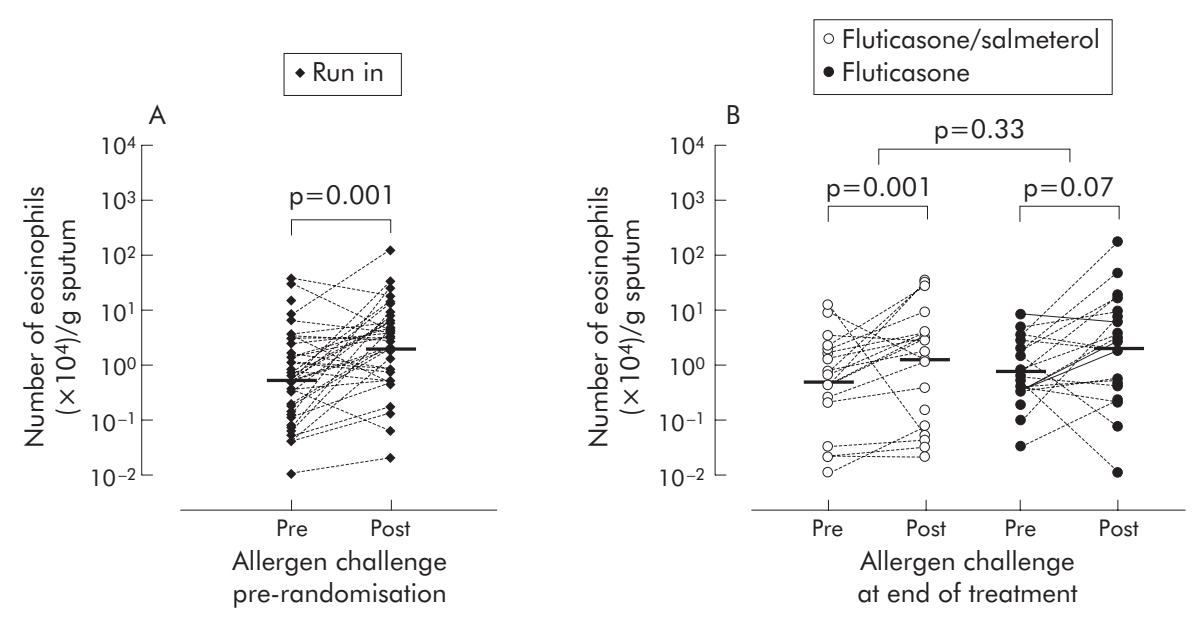

Figure 5 Numbers of sputum eosinophils before and after bronchial allergen challenges (A) before randomisation and (B) at the end of treatment. Geometric mean numbers of sputum eosinophils increased significantly after both the pre-randomisation and the end of treatment allergen challenge. There was no significant difference between the two treatment groups between the increases in sputum eosinophils after the end of treatment allergen challenge $(p=0.33)$.

as well as after the end of treatment allergen challenge (table 4).

There was a trend for a smaller increase in the percentage of sputum eosinophils in the fluticasone/salmeterol group after the end of treatment allergen challenge $(p=0.09)$, but there were no significant differences between the two treatment groups after the end of treatment allergen challenge in the changes in numbers of sputum eosinophils and ECP concentrations (table 4).

Sputum neutrophils, IL-8, MPO and serum IL-5 The number of sputum neutrophils, sputum IL-8, sputum MPO, and serum IL-5 increased after the pre-randomisation allergen challenge $(\mathrm{p}<0.001,0.001,0.005$ and $<0.001$, respectively) as well as after the end of treatment allergen challenge $(p=0.02,0.06,0.02$, and 0.02 , respectively, data not shown). There were no significant differences between the two treatment groups in the changes in these parameters after the end of treatment allergen challenge $(p=0.92,0.85$, 0.93 and 0.89 , respectively, data not shown).

\section{Size selectivity of the respiratory membrane:} relative coefficient of excretion $\left(R C E_{s}\right)$

There was no significant difference between the two treatment groups in the changes in the $\mathrm{RCE}_{\mathrm{s}}$ after the end of treatment allergen challenge $(p=0.15$, table 4$)$. Likewise, there were no significant differences between the two treatment groups in the changes in sputum $\alpha_{2}$-macroglobulin or albumin after the end of treatment allergen challenge (table 4).

\section{DISCUSSION}

This is the first randomised clinical trial to investigate over a 1 year treatment period whether the improved clinical outcomes resulting from adding salmeterol to fluticasone are accompanied by an additional effect on bronchial inflammation. In agreement with earlier studies, peak expiratory flows, symptom scores, rescue medication usage, and bronchial hyperresponsiveness were significantly improved in the fluticasone/salmeterol group relative to the fluticasone group. Similar levels of sputum eosinophils, sputum ECP, sputum IL-8, sputum MPO, and serum IL-5 were found in both groups throughout the treatment period as well as after the bronchial allergen challenges. However, we did find significantly reduced ratios of sputum $\alpha_{2}$ macroglobulin and albumin in the fluticasone/salmeterol group relative to the fluticasone group. This secondary outcome, the relative coefficient of excretion $\left(\mathrm{RCE}_{\mathrm{s}}\right)$, was chosen as a marker of size selectivity of plasma protein permeation across the respiratory membrane.

The lack of a sustained effect of adding salmeterol on cellular bronchial inflammation, as found in induced sputum, is in agreement with a recent study by Overbeek et $a l^{8}$ who failed to show an additional anti-inflammatory effect in bronchial biopsy specimens of adding formeterol to low doses of budesonide during 16 weeks of treatment. Earlier in vitro $^{23} 24$ and short term in vivo studies ${ }^{67}$ did report an initial anti-inflammatory effect which may be in line with our observation of a transient decrease in the number of sputum eosinophils 1 month after randomisation in the fluticasone/ salmeterol group. This difference in sputum eosinophils at

Table 4 Allergen induced increase in inflammatory parameters

\begin{tabular}{|c|c|c|c|c|}
\hline & \multirow{2}{*}{$\begin{array}{l}\text { Pre-randomisation } \\
\text { allergen challenge } \\
(n=54)\end{array}$} & \multicolumn{2}{|c|}{ End of treatment allergen challenge } & \multirow[b]{2}{*}{$\begin{array}{l}p \text { value } \\
\text { FP } \vee \text { FP } / S\end{array}$} \\
\hline & & $\begin{array}{l}\text { Fluticasone (FP) } \\
(n=23)\end{array}$ & $\begin{array}{l}\text { Fluticasone/salmeterol (FP/S) } \\
(\mathrm{n}=27)\end{array}$ & \\
\hline Sputum eosinophils (n) & $3.7(1.9$ to 7.1$)$ & $4.4(2.4$ to 8.1$)$ & $2.6(1.0$ to 6.8$)$ & 0.33 \\
\hline Sputum eosinophils (\%) & $2.4(1.5$ to 3.8$)$ & $3.4(1.9$ to 6.1$)$ & $1.8(0.9$ to 3.8$)$ & 0.09 \\
\hline Sputum ECP & 2.0 (1.2 to 3.4$)$ & 2.1 (1.0 to 4.4$)$ & $1.4(0.7$ to 2.5$)$ & 0.18 \\
\hline $\mathrm{RCE}_{\mathrm{s}}$ & $1.4(1.0$ to 1.8$)$ & $0.8(0.5$ to 1.3$)$ & $1.3(0.9$ to 1.8$)$ & 0.15 \\
\hline Sputum $\alpha_{2}$-macroglobulin & $1.3(1.0$ to 1.7$)$ & $1.2(0.7$ to 2.0$)$ & $1.0(0.7$ to 1.5$)$ & 0.34 \\
\hline Sputum albumin & $0.9(0.6$ to 1.3$)$ & $1.5(0.9$ to 2.5$)$ & $0.8(0.5$ to 1.3$)$ & 0.27 \\
\hline
\end{tabular}


1 month after the pre-randomisation allergen challenge may be explained by a slower recovery from the allergen induced increase in bronchial inflammation in the fluticasone group. Bronchial allergen challenge increases levels of inflammatory markers, ${ }^{25}$ which may increase the sensitivity to detect differences in levels of inflammatory markers between the treatment groups. On the other hand, it should be noted that the medium to high daily dose of fluticasone resulted in relatively low baseline levels of the inflammatory parameters. This may have obscured a modest long term anti-inflammatory effect on cellular bronchial inflammation of adding salmeterol. The study was powered to detect a $50 \%$ difference in primary outcomes (sputum eosinophils and ECP) between the groups, since such a difference was considered to be clinically relevant. Therefore, adding salmeterol to an inhaled corticosteroid under the conditions chosen neither causes a clinically relevant deleterious or masking long term effect on cellular bronchial inflammation nor significantly improves it. It should be emphasised that this finding may be unique to the administration of the combination product of salmeterol and fluticasone as patients may be tempted to leave off the latter when using both medications separately. It was reported previously that reducing the dose of inhaled corticosteroids in patients on salmeterol can mask increasing inflammation and delay awareness of worsening asthma. ${ }^{14}$

With respect to the effects on allergen induced bronchial inflammation, it should be stressed that patients abstained from the study medication for 12 hours before every visit, including the allergen challenge visits. This may have obscured an acute effect of adding salmeterol to fluticasone, but the aim of the study was to investigate the long term rather than the acute effects of fluticasone/salmeterol versus fluticasone on allergen induced bronchial inflammation. We, like others, have found indications in vivo for an acute short term anti-inflammatory effect of the addition of salmeterol to inhaled corticosteroids in a bronchial allergen challenge model. ${ }^{26}$

A concomitant characteristic of the bronchial cellular inflammatory process is the presence of increased permeability of the respiratory membrane. ${ }^{27}$ In healthy subjects the permeation of large plasma proteins is restricted, but during inflammation there is an apparent loss of size selectivity of the respiratory membrane.22 This will affect the sputum concentration of large plasma proteins more than of smaller proteins. The ratio of sputum levels of a large plasma protein $\left(\alpha_{2}\right.$-macroglobulin) to levels of a smaller plasma protein (albumin) is considered a marker of size selectivity of the barrier between the blood and the airway lumen. ${ }^{13}$ We particularly chose this ratio since it is not influenced by variable dilution of sputum samples. Over the run-in period, when all patients received fluticasone $250 \mu \mathrm{g}$ twice daily, we found a significant decrease in the $\mathrm{RCE}_{\mathrm{S}}$. This finding is in keeping with an earlier study. ${ }^{13}$ Moreover, we found a continued decrease in the $\mathrm{RCE}_{\mathrm{s}}$ in the fluticasone/salmeterol group throughout the randomised treatment period, whereas the $\mathrm{RCE}_{\mathrm{s}}$ stabilised in the fluticasone group. This finding may point to increased size selectivity of the respiratory membrane caused by adding salmeterol. This is in keeping with earlier studies showing anti-exudative short term effects of long acting $\beta_{2}$ agonists in animal ${ }^{28} 29$ as well as in human models. ${ }^{30}$ Such an anti-exudative effect may be desirable in the treatment of asthma, since the extravasated plasma contains potent adhesive and leucocyte activating proteins (such as fibrinogen and fibronectin) and inflammatory peptides including bradykinins and complement factors. ${ }^{31}$ However, analysis of the sputum concentrations of the individual serum proteins suggested an increase in albumin rather than a decrease in $\alpha_{2}$-macroglobulin in the fluticasone/ salmeterol arm throughout the randomised treatment period.
This might be explained by increased water clearance by salmeterol, which has been shown in animal models, ${ }^{32}{ }^{33}$ in addition to increased size selectivity. An alternative explanation for the decrease in $\mathrm{RCE}_{\mathrm{s}}$ may be provided by the occurrence of selective transport of serum albumin to the airway lumen. In vitro, active transport of albumin across the ferret trachea has been reported which was increased by the short acting $\beta_{2}$ agonist salbutamol. ${ }^{34}$ Moreover, specific serum albumin binding proteins have been identified. ${ }^{35}$ The role of albumin in the airway secretions is at present unclear. There is evidence that albumin may bind various mediators such as leukotrienes ${ }^{36}$ and may therefore render potentially active luminal agents less effective. Albumin may also act as a luminal antioxidant, preventing the formation of oxygen free radicals. ${ }^{37}$ In this respect, increased levels of albumin in sputum may have physiological advantages.

In summary, we have shown that improved clinical outcomes resulting from adding a long acting $\beta_{2}$ agonist to maintenance treatment with inhaled corticosteroids are accompanied by similar levels of markers of chronic as well as allergen induced cellular bronchial inflammation. However, size selectivity of plasma protein permeation across the respiratory membrane appeared to be significantly improved by adding salmeterol to fluticasone, and this may contribute to the improved clinical outcomes seen.

\section{ACKNOWLEDGEMENTS}

The authors thank Barbara Smids-Dierdorp, Tamara Dekker, and Marianne van de Pol for their work on the inflammatory parameters in this study.

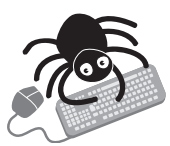

An extended version of the Methods section is available in the online data supplement at http:// www.thoraxjnl.com/supplemental.

\section{Authors' affiliations}

J G Koopmans, H M Jansen, J S van der Zee, Department of Pulmonology, Academic Medical Center, University of Amsterdam, Amsterdam, The Netherlands

R Lutter, Laboratory of Experimental Immunology, Academic Medical Center, University of Amsterdam, Amsterdam, The Netherlands

This study was supported by a grant from GlaxoSmithKline.

The Department of Pulmonology and Laboratory of Experimental Immunology, Academic Medical Center, University of Amsterdam, Amsterdam, The Netherlands receive research grants from GlaxoSmithKline, Numico and AstraZeneca for performing trials. The author and co-authors of this manuscript have no financial relationship with a commercial entity that has an interest in the subject of this manuscript.

\section{REFERENCES}

1 Global Initiative for Asthma (GINA). Global strategy for asthma management and prevention, NHLBI/WHO Workshop Report.Report No 02-3659. Bethesda, MD: National Institutes of Health, National Heart Lung and Blood Institute, 2002.

2 Laitinen LA, Laitinen A, Haahtela T. A comparative study of the effects of an inhaled corticosteroid, budesonide, and a beta 2-agonist, terbutaline, on airway inflammation in newly diagnosed asthma: a randomized, doubleblind, parallel-group controlled trial. J Allergy Clin Immunol 1992;90:32-42.

3 Pauwels RA, Lofdahl CG, Postma DS, et al. Effect of inhaled formoterol and budesonide on exacerbations of asthma. Formoterol and Corticosteroids Establishing Therapy (FACET) International Study Group. N Engl J Med 1997;337:1405-11.

4 Shrewsbury S, Pyke S, Britton M. Meta-analysis of increased dose of inhaled steroid or addition of salmeterol in symptomatic asthma (MIASMA). BMJ 2000;320:1368-73.

5 Taylor DR, Hancox RJ. Interactions between corticosteroids and beta agonists. Thorax 2000;55:595-602.

6 Li X, Ward C, Thien F, et al. An antiinflammatory effect of salmeterol, a longacting beta(2) agonist, assessed in airway biopsies and bronchoalveolar lavage in asthma. Am J Respir Crit Care Med 1999;160:1493-9. 
7 Wallin A, Sue-Chu M, Bjermer L, et al. Effect of inhaled fluticasone with and without salmeterol on airway inflammation in asthma. J Allergy Clin Immunol 2003; 112:72-8.

8 Overbeek SE, Mulder PG, Baelemans SM, et al. Formeterol added to low-dose budesonide has no additional antiinflammatory effect in asthmatic patients. Chest 2005; 128:1121-7.

9 Dompeling E, van Schayck CP, van Grunsven PM, et al. Slowing the deterioration of asthma and chronic obstructive pulmonary disease observed during bronchodilator therapy by adding inhaled corticosteroids. A 4-year prospective study. Ann Intern Med 1993;118:770-8.

10 Selroos $O$, Pietinalho $A$, Lofroos $A B$, et al. Effect of early vs late intervention with inhaled corticosteroids in asthma. Chest 1995;108:1228-34.

11 Sont JK, Han J, van Krieken JM, et al. Relationship between the inflammatory infiltrate in bronchial biopsy specimens and clinical severity of asthma in patients treated with inhaled steroids. Thorax 1996;51:496-502.

12 Aldridge RE, Hancox RJ, Robin TD, et al. Effects of terbutaline and budesonide on sputum cells and bronchial hyperresponsiveness in asthma. Am J Respir Crit Care Med 2000;161:1459-64.

13 Nocker RE, Weller FR, Out TA, et al. A double-blind study on the effect of inhaled corticosteroids on plasma protein exudation in asthma. Am J Respir Crit Care Med 1999; 159:1499-505.

14 Mcivor RA, Pizzichini E, Turner MO, et al. Potential masking effects of salmeterol on airway inflammation in asthma. Am J Respir Crit Care Med 1998; 158:924-30

15 Sterk PJ, Fabbri LM, Quanjer PH, et al. Airway responsiveness. Standardized challenge testing with pharmacological, physical and sensitizing stimuli in adults. Report of Working Party on Standardization of Lung Function Tests, European Community for Steel and Coal. Official Statement of the European Respiratory Society. Eur Respir J Suppl 1993;16:53-83.

16 Witteman AM, Stapel SO, Perdok GJ, et al. The relationship between RAST and skin test results in patients with asthma or rhinitis: a quantitative study with purified major allergens. J Allergy Clin Immunol 1996;97:16-25.

17 Nocker RE, Out TA, Weller FR, et al. Induced sputum and bronchoalveolar lavage as tools for evaluating the effects of inhaled corticosteroids in patients with asthma. J Lab Clin Med 2000; 136:39-49.

18 Reimert CM, Venge $P$, Kharazmi A, et al. Detection of eosinophil cationic protein (ECP) by an enzyme-linked immunosorbent assay. J Immunol Methods $1991 ; 138: 285-90$.

19 Bresser P, Out TA, van Alphen L, et al. Airway inflammation in nonobstructive and obstructive chronic bronchitis with chronic Haemophilus influenzae airway infection. Comparison with noninfected patients with chronic obstructive pulmonary disease. Am J Respir Crit Care Med 2000; 162:947-52

20 Nocker RE, Schoonbrood DF, van de Graaf EA, et al. Interleukin-8 in airway inflammation in patients with asthma and chronic obstructive pulmonary disease. Int Arch Allergy Immunol 1996;109:183-91.

21 McNamee LA, Fattah DI, Baker TJ, et al. Production, characterisation and use of monoclonal antibodies to human interleukin-5 in an enzyme-linked immunosorbent assay. J Immunol Methods 1991;141:81-8.
22 van de Graaf EA, Out TA, Roos CM, et al. Respiratory membrane permeability and bronchial hyperreactivity in patients with stable asthma. Effects of therapy with inhaled steroids. Am Rev Respir Dis $1991 ; 143: 362-8$.

23 Eickelberg $O$, Roth $M$, Lorx $R$, et al. Ligand-independent activation of the glucocorticoid receptor by $\beta_{2}$-adrenergic receptor agonists in primary human lung fibroblasts and vascular smooth muscle cells. J Biol Chem 1999;274:1005-10.

24 Pace E, Gagliardo R, Melis M, et al. Synergistic effects of fluticasone propionate and salmeterol on in vitro T-cell activation and apoptosis in asthma. J Allergy Clin Immunol 2004; 1 14:1216-23.

25 Lopuhaa CE, Out TA, Jansen HM, et al. Allergen-induced bronchial inflammation in house dust mite-allergic patients with or without asthma. Clin Exp Allergy 2002;32:1720-7.

26 Koopmans JG, Lutter R, Jansen HM, et al. Adding salmeterol to an inhaled corticosteroid reduces allergen-induced serum IL-5 and peripheral blood eosinophils. J Allergy Clin Immunol 2005;116:1007-13.

27 Persson CG. Plasma exudation and asthma. Lung 1988;166:1-23.

28 Bolton PB, Lefevre P, McDonald DM. Salmeterol reduces early- and late-phase plasma leakage and leukocyte adhesion in rat airways. Am J Respir Crit Care Med 1997; 155:1428-35.

29 Erjefalt JS, Korsgren M, Malm-Erjefalt $M$, et al. Acute allergic responses induce a prompt luminal entry of airway tissue eosinophils. Am J Respir Cell Mol Biol 2003;29:439-48.

30 Greiff $L$, Wollmer $P$, Andersson $M$, et al. Effects of formoterol on histamine induced plasma exudation in induced sputum from normal subjects. Thorax 1998;53:1010-3.

31 Persson CG, Erjefalt JS, Greiff L, et al. Plasma-derived proteins in airway defence, disease and repair of epithelial injury. Eur Respir J 1998; 11:958-70.

32 Frank JA, Wang $Y$, Osorio $O$, et al. Beta-adrenergic agonist therapy accelerates the resolution of hydrostatic pulmonary edema in sheep and rats. J Appl Physiol 2000;89:1255-65.

33 McAuley DF, Frank JA, Fang X, et al. Clinically relevant concentrations of beta2-adrenergic agonists stimulate maximal cyclic adenosine monophosphate-dependent airspace fluid clearance and decrease pulmonary edema in experimental acid-induced lung injury. Crit Care Med 2004;32: 1470-6.

34 Webber SE, Widdicombe JG. The transport of albumin across the ferret in vitro whole trachea. J Physiol 1989;408:457-72.

35 Schnitzer JE, Oh P. Albondin-mediated capillary permeability to albumin. Differential role of receptors in endothelial transcytosis and endocytosis of native and modified albumins. J Biol Chem 1994;269:6072-82.

36 Gutteridge JM. Antioxidant properties of the proteins caeruloplasmin albumin and transferrin. A study of their activity in serum and synovial fluid from patients with rheumatoid arthritis. Biochim Biophys Acto 1986;869:119-27 